Syntax Fusion : Jurnal Nasional Indonesia

P-ISSN: $x x x x-x x x x$

e-ISSN : $x x x x-x x x x$

Vol. 1, No. 1, Oktober 2020

\title{
PENGARUH TEKNIK RELAKSASI NAPAS DALAM TERHADAP PENURUNAN SAKIT HAID PADA REMAJA PUTRI DI WILAYAH KERJA UPTD PUSKESMAS PANGLAYUNGAN KOTA TASIKMALAYA
}

\author{
Rica Arieb Shintami, Rosidah Rosidah \\ Poltekkes Bhakti Pertiwi Husada Cirebon \\ Email : ricaarieb85@gmail.com, ndakeenar@gmail.com \\ Abstrak
}

Sakit haid (dismenorhea) atau Sakit menstruasi adalah karakteristik Sakit yang terjadi sebelum atau selama menstruasi. Hari pertama sampai beberapa hari kedepan selama menstruasi, rasa sakit ketika sedang mengalami sangat dapat menyiksa diri bagi seluruh wanita. Rasa Sakit seperti tertusuk di sekitar bagian perut bawah dan kadang ppula mengalami hal kesulitan untuk berjalan yang sering terjadi ketika haid menyerang.

Dalam tujuan penelitian ini salah satunya adalah untuk dapat mengetahui terhadap Pengaruh Teknik Relaksasi Napas Dalam Terhadap Penurunan Sakit Haid Pada Remaja Putri di Wilayah Kerja UPTD Puskesmas Panglayungan Kota Tasikmalaya tahun 2020.

Pada penelitian ini, jenis penelitian yang digunakan adalah penelitian kuantitatif, dimana penelitian ini bersifat deduktif, objektif dan ilmiah dimana dapat diperoleh berupa angka, nilai atau pertanyaan-pertanyaan yang dapat dinilai, dan menganalisis dengan analisis statistic. Populasi ini sering terjadi dalam penelitian kepada semua remaja putri yang mengalami Sakit haid di UPTD Puskesmas Panglayungan Kota Tasikmalaya sejumlah 50 orang, Pemilihan anggota sampel berdasarkan penilaian (judgment) mengenai siapa siapa saja yang meneliti maka pantas untuk memenuhi syarat yang dijadikan sampel sebanyak 20 orang karena 30 orang tidak sesuai dengan kriteria inklusi maupun kriteria eksklusi yang ditentukan. Analisis data menggunakan bivariat (paired sample $t$ - test).

Hasil penelitian menunjukan bahwa Skala Sakit Haid pada remaja putri sebelum diberikan intervensi Teknik Relaksasi Napas di UPTD Puskesmas Panglayungan Kota Tasikmalaya sebagian besar mengalami Sakit sedang sebanyak 16 remaja putri (80\%). Skala Sakit Haid pada remaja putri sesudah diberikan intervensi Teknik Relaksasi Napas di UPTD Puskesmas Panglayungan Kota Tasikmalaya sebagian besar mengalami Sakit ringan sebanyak 13 remaja putri (65\%). Ada pengaruh Teknik Relaksasi Napas terhadap sakit Haid yang dialami remaja putri di UPTD Puskesmas Panglayungan Kota Tasikmalaya dengan tingkat signifikasi $\alpha$ $=0.05$ diperoleh hasil $p=0,002$ yang berarti $p<0,05$. 
Diharapkan untuk melakukan Teknik Relaksasi Napas secara teratur bila merasakan Sakit saat haid, tidak memaksakan diri melakukan aktifitas hingga selesai agar badan tidak lelah.

\section{Kata Kunci: Teknik Relaksasi Napas dalam, Sakit Haid, Remaja Putri}

\section{Pendahuluan}

Masa remaja merupakan masa dengan periode perkembangan yang ditandai dengan munculnya jenis ciri seksual sekunder serta pematangan fungsi organ seksual seperti ovulasi dan menstruasi (Esen, Oğuz \& Serin, 2016). Menstruasi dapat didefinisikan menjadi suatu bahan perubahan fisiologis di tubuh wanita secara menerus yang dipengaruhi oleh hormon reproduksi. Menstruasi dapat mengacu kepada pendarahan dan sel sel tubuh secara periodik dibagian dinding vagina kewanitaan (Pratiwi, 2011).

Gangguan ini sering sekali timbul saat menstruasi yaitu haid/dismenorea. Rasa Sakit Haid/Dismenorea merupakan salah satu keluhan yang disebut ginekologis yang mengakibatkan ketidak seimbangan pada hormone progesterone dalam darah, sehingga dapat mengakibatkan rasa Sakit yang sering sekali terjadi pada wanita (Lestari, 2013).

Berdasarkan hasil data riset dari berbagai negara di belahan dunia, bahwa angka yang sering terjadi akibat kejadian dismenorea cukup tinggi. Diperkirakan bisa mencapai lebih dari 50 sampai $75 \%$ yang menderita dismenora dalam siklus ini.

Studi epidemiologi pada usia dari banaknya populasi remaja yang menginjak usia 12-17 tahun di Amerika Serikat, faktor resiko dismenorea mencapai 59,7\%. Dari yang dimulai dengan rasa keluhan sakit mencapai 12\% dengan sakit berat, 37\% Sakit sedang, dan 49\% Sakit ringan (Ernawati, 2016).

Di Indonesia angka sebesar 64\% yang terdiri dari 54,89\% desmenorea primer dan $9,36 \%$ dismenorea sekunder. Dismenore primer biasanya dapat terjadi pada wanita dengan usia produktif 1-5 tahun setelah mengalami sakit mestruasi pertama dan yang belum memasukin fase kehamilan (Haspari, 2015). Insiden ini dilaporkan mencapai 92\%, dan dengan seiringnya waktu bertambah usia serta meningkatkan angka kelahiran. Puncak dari insiden dismenoreaprimer ini terjadi pada masa akhir usia remaja dengan awal usia yang menginjak 20an tahun (Ernawati, 2010). Angka pada Provinsi Jawa Barat dalam kejadian dismenorea yang dialami oleh wanita saat menstruasi mencapai $53 \%$ dan hanya $1,07 \%-1,31 \%$ dari jumlah penderita dismenorea dating ke petugas kesehatan (Noravita, 2017).

Sakit haid (dismenorhea) atau Sakit menstruasi adalah karakteristik Sakit yang terjadi sebelum atau selama menstruasi. Pada hati pertama ketika terjadi sampai beberapa hari kedepannya selama menstruai, rasa Sakit tentu saja sangat menyiksa pada wanita, Sakit yang menusuk dan Sakit hebat yang dialami di bagian perut bawah bahkan kadang mengalami kesulitan untuk berjalan jauh ketika menstruasi datang menyerang (Harahap, 2011).

Beberapa yang dikeluhkan wanita pada penyakit menstruasi yaitu mual yang mengakibatkan muntah, diare dan kram pada perut seperti kolik di perut atau yang sering 
diketahui yaitu nyeri yang sangat hebat pada perut yang sifatnya hilang kemudian timbul kembali. Beberapa wanita ataupun banyaknya wanita yang mengalami haid dipastikan mengalami pingsan dan mabuk, dengan keadaan yang sering muncul cukup hebat sehingga dapat mengakibatkan kelumpuhan beraktifitas untuk sementara (Saryono, 2013).

Saat menstruasi, sering terjadinya keluhan pada wanita dengan usia produktif. Sebagian wanita, ketika menjelang menstruasi seringnya merasakan hal yang sangat tidak nyaman bahkan seringnya mengganggu aktifitas sehari hari, seperti Sakit perut dibagian pinggang, mual ataupun pusing (Kasdu, 2015).

Penyakit datang bulan adalah salah satu bagian dari sebuah proses yang mempersiapkan tubuh waita untuk kehamilan. Kondisi ini menjadi sangat tidak menyenangkan karena perasaan yang berbeda dalam skala atau tingkatannya, bahkan hanya wanita tersebutlah yang dapat menjelaskan dan mengevaluasi rasa sakit yang diderita. Sakit ini sebagai acuan dari suatu keadaan yang terjadi akibat rangsangan fisik dari saraf ke otak yang membuatnya tidak menyenangkan dan diikuti oleh reaksi pada fisiknya, fisiologi, dan emosional. Wanita yang mengalami sakit menstruasi (dismenorea) yaitu memproduksi prostaglandin 10 kali lebih banyak dari wanita yang tidak dismenorea.

Prostaglandin dapat menyebabkan tingkatan dalam kontraksi uterus dan kadar yang berlebihan pada sktivasi usus besar. (Prawirohardjo, 2011). Dengan rasa yang sangat tidak nyaman jika tidak diatasi mengakibatkan berpengaruhnya fungsi mental dan fisik sehingga mendesak untuk segera mengambil tindakan secara terapi farmakologis atau non farmakologis. Dalam terapi farmakologis atau holistic dapat mengatasi Sakit dengan menggunakan sentuhan terapeutik, akupresur dan relaksasi. Teknik relaksasi ini dapat membantu memberikan control diri ketika sedang terjadinya rasa Sakit serta dapat digunkan pada saat sehat ataupun Sakit (Siregar, 2015).

Untuk mengatasi Sakit haid (dismenore) dapat dilakukan dengan terapi farmakologi dan non farmakologi. Terapi non farmakologi dapat dilakukan salah satunya dengan menggunakan teknik relaksasi. Dari teknik relaksasi nafas ini, bentuk suatu asuhan keperawatan yang akan dilakukan dengan cara melakukan nafas dalam atau nafas perlahan (menahan inspirasi secara maksima), dengan megatur hembusan nafas secara perlahan. Selain dapat mengurangi intensitas Sakit, teknik ini juga dapat meningkatkan ventilasi pada paru-paru dan dapat meningkatkan oksigenasi darah (Azizah, 2013).

Dalam teknik relaksasi yang dilakukan secara berulang akan menimbulkan rasa nyaman. Adanya rasa nyaman inilah yang akhirnya akan meningkatkan toleransi seseorang terhadap Sakit. Orang yang memiliki toleransi Sakit yang baik akan mampu beradaptasi terhadap Sakit dan akan memiliki mekanisme koping yang baik pula. Selain meningkatkan toleransi Sakit, rasa nyaman yang dirasakan setelah melakukan metode relaksasi pernafasan dapat meningkatkan ambang sakit sehingga dengan meningkatkan ambang sakit yang terjadi berada pada skala 2 (sakit sedang) menjadi skala 1 (sakit ringan) sesudah dilakukannya teknik relaksasi pernafasan dalam (Ernawati dkk, 2010)

Menurut penelitian dari Hapsari (2013) teknik relaksasi napas dalam efektif untuk menurunkan sakit dimenore. Menurut penelitian dari Azizah (2013) teknik relaksasi 
napas dalam juga efektif karena merupakan teknik pengendoran atau pelepasan ketegangan, teknik napas dalam juga dapat meningkatkan ventilasi paru dan meningkatkan oksigen darah.

Studi pendahuluan dilakukan pada bulan Maret 2020 di Wilayah Kerja UPTD Puskesmas Panglayungan Kota Tasikmalaya total jumlah kunjungan pasien yang mengalami sakit saat haid / dismenore yaitu sebanyak 50 kasus, tahun 2018 meningkat sebanyak 162 kasus, dan tahun 2019 terdapat 153 kasus. Berdasarkan hasil wawancara terhadap 10 orang sebanyak 7 orang $70 \%$ menunjukkan pasien belum mengetahui manfaat dan prosedur dari teknik relaksasi nafas dalam. Pasien melakukan penanganan dismenore dengan istirahat ditempat tidur dan terkadang pasien tidak melakukan apa-apa.

Oleh karena itu dilatar belakang hal ini, peneliti tertarik untuk melakukan riset penelitian tentang Pengaruh Teknik Relaksasi Napas Dalam Terhadap Penurunan Sakit Haid Pada Remaja Putri di Wilayah Kerja UPTD Puskesmas Panglayungan Kota Tasikmalaya sehingga diharapkan metode ini dapat digunakan sebagai terapi non farmakologis yang mudah dan aplikatif terhadap penurunan intensitas pada remaja yang sedang mengalami haid.

\section{Metode Penelitian}

Pada penelitian ini, jenis penelitian yang digunakan adalah penelitian kuantitatif, dimana penelitian ini bersifat deduktif, objektif dan ilmiah dimana data dapat diperoleh berupa angka atau skor bahkan pertanyaan-pertanyaan yan dinilai serta dilakukan analisis dengan analisis statistik. Populasi dalam pembahasan ini ialah seluruh remaja putri yang mengalami Sakit haid di UPTD Puskesmas Panglayungan Kota Tasikmalaya sejumlah 50orang, Pemilihan anggota sampel berdasarkan penilaian (judgment) peneliti mengenai siapa-siapa saja yang pantas (memenuhi persyaratan) untuk dijadikan sampel sebanyak 20 orang karena 30 orang tidak sesuai dengan kriteria inklusi maupun kriteria eksklusi yang ditentukan. Analisis data menggunakan bivariat (paired sample $t-t e s t$ ).

\section{Hasil dan Pembahasan}

A. Skala Sakit Haid pada remaja putri sebelum diberikan intervensi berupa Teknik Relaksasi Napas di Wilayah Kerja UPTD Puskesmas Panglayungan Kota Tasikmalaya.

Berdasarkan hasil penelitian, diketahui bahwa Sakit Haid pada remaja putri sebelum diberikan intervensi Teknik Relaksasi Napas di UPTD Puskesmas Panglayungan Kota Tasikmalaya sebagian besar mengalami Sakit sedang sebanyak 16 remaja putri $(80 \%)$.

Menurut Kushariyadi (2011), relaksasi pernafasan dalam ini adalah suatu pernafasan abdomen dengan mengakibatkan suatu frekuensi lambat atau perlahan, berirama, dan kenyamanan yang akan dilakukan dengan menutupkan mata, sehingga dalam tindakanini yang akan menstimulasi sistem control dependen atau system serabut yang diawali dari dalam otak bagian bawah dan ke bagian tengah yang akan berakhir pada 
pada serabut interneural inhibitor dalam mengkornudorsalis serta medulla spinalis yang dapat menyebabkan kurangnya stimulus transmisi ke otak.

Kejadian Sakit Haid sangat berpengaruh pada usia kaum wanita. Rasa sakit yang akan dirasakan beberapa hari sebelum terjadinya menstruasi dan saat menstruasi biasanya karena meningkatnya sekresi hormon prostaglandin. Semakin tua umur seseorang, maka semakin seringlah ia mengalami penyakit bulanan dan semakin melebar pula leher rahim maka sekresi hormone prostaglandin berkurang. Selain itu, sakit haid akan perlahan menghilang dengan menurunnya fungsi pada saraf rahim akibat terjadinya penuaan.

Gejala yang dialami saat menstruasi sesuai dengan pendapat Judha (2012) gejala yang dirasakan pada saat dismenore adalah sakit pada perut bagian bawah, pinggang bahkan punggung. Dismenore sangat mengganggu aktivitas dan sering dikeluhkan pada sebelum, saat dan setelah menstruasi. Sakit tersebut timbul akibat terdapat hormone prostaglandin yang dapat membuat oto rahim berkontraksi (Judha, dkk, 2012)

\section{B. Sakit Haid pada remaja putri sesudah diberikan intervensi berupa Teknik Relaksasi Napas di UPTD Puskesmas Panglayungan Kota Tasikmalaya.}

Berdasarkan hasil penelitian diketahui bahwa Sakit Haid pada remaja putri sesudah diberikan intervensi Teknik Relaksasi Napas di UPTD Puskesmas Panglayungan Kota Tasikmalaya sebagian besar mengalami Sakit ringan sebanyak 13 remaja putri $(65 \%)$.

Hasil tersebut menunjukkan adanya perbedaan yang bermakna pada rata-rata intensitas Sakit sesudah dilakukan relaksasi nafas dalam atau dengan kata lain secara signifikan bahwa relaksasi nafas dalam dapat menurunkan rata-rata intensitas Sakit sebesar 4,70 $(\alpha<0,05)$.

Responden yang mengalami Sakit Haid dianjurkan pada saat melakukan relaksasi nafas dalam harus dalam keadaan rileks dengan posisi yang nyaman, tenang dan tidak terdapat beban pikiran. D'Silva dan Muninarayanappa (2014) menyebutkan bahwa dengan relaksi nafas dalam merupakan metode yang efektif dalam mengurangi rasa sakit pada pasien yang dialaminya dengan sakit kronis. Relaksasi akan sempurna dengan mengurangi ketegangan otot, rasa jenuh dan kecemasan yang mencegah hebatnya stimulus.

Sakit Haid yang dialami responden sesaat sebelum dilakukan teknik relaksasi nafas dalam, keadaan responden tidak rileks dan pikiran responden hanya tertuju pada sakit tanpa melakukan relaksasi terhadap sakit yang dirasakan. Teknik relaksasi nafas dalam yang dilakukan oleh responden hanya berfokus pada daerah yang mengalami Sakit atau ketegangan otot pada perut bagian bawah dan merelaksasi perut bagian bawah yang mengalami sakit atau ketegangan otot sampai responden mencapai relaksasi penuh.

Kegiatan relaksasi nafas dalam menciptakan sensasi melepaskan ketidaknyamanan dan stres. Secara bertahap, kilen yang sedang mengalami menstruasi dapat merelaksasikan otot perut tanpa harus menegangkan otot perut. Saat klien mencapai relaksasi penuh, maka otak akan mngaktivasi gelombang alfa di otak dan merangsang 
hipotalamus mengeluarkan hormone endorphine sehingga menimbulkan persepsi sakit yang berkurang dan rasa kecemasam terhadap pengalaman sakit menjadi minimal.

Setelah diberikan intervensi relaksasi nafas dalam terjadi penurunan intensitas Sakit dari 16 responden yang mengalami Sakit sedang 10 diantaranya menurun menjadi Sakit ringan dan 6 responden lainnya tidak mengalami Sakit lagi. Kemudian dari 1 responden yang mengalami Sakit ringan setelah diberi intervensi tidak mengalami Sakit lagi dan 3 responden yang mengalami Sakit berat menurun menjadi Sakit ringan. Skala tersebut menunjukkan bahwa Sakit yang dirasakan responden sesudah relaksasi nafas dalam adalah tidak Sakit dan Sakit ringan.

Responden yang mengalami dismenore dituntut pada saat melakukan relaksasi nafas dalam harus dalam keadaan rileks, posisi yang nyaman, tenang dan tidak terdapat beban pikiran. Ulangi sampai 15 kali nafas dengan diselingi istirahat singkat setiap 5 kali. Pada saat penelitian responden mengikuti arahan dengan sangat baik sehingga dapat menurunkan Sakit dismenore yang sedang dialami dengan baik pula.

\section{Pengaruh Teknik Relaksasi Napas terhadap Sakit Haid pada remaja putri di UPTD Puskesmas Panglayungan Kota Tasikmalaya.}

Berdasarkan hasil penelitian uji statistik menggunakan uji Uji Independent T Test, dengan bantuan SPSS versi 24 dengan tingkat signifikasi $\alpha=0.05$ diperoleh hasil $\mathrm{p}=$ 0,002 yang berarti $\mathrm{p}<0,05$ yaitu $\mathrm{H} 1$ diterima yang artinya ada pengaruh Teknik Relaksasi Napas terhadap Sakit Haid pada remaja putri di UPTD Puskesmas Panglayungan Kota Tasikmalaya.

Hasil penelitian ini menunjukkan bahwa relaksasi nafas dalam dapat menurunkan intensitas Sakit haid secara signifikan sehingga menunjukkan perbedaan yang signifikan antara skala intensitas Sakit sebelum dan sesudah dilakukan relaksasi nafas dalam.

Dalam penelitian yang dilakukan oleh Vetty Priscilla, dkk (2012) dengan judul penelitian Perbedaan Pengaruh Teknik Relaksasi Nafas Dalam Dan Kompres Hangat Dalam Menurunkan Sakit Haid Pada Remaja di SMA Negeri 3 Padang dengan jumlah jumlah responden 32 remaja putri yang dibagi menjadi dua kelompok intervensi dan durasi relaksasi nafas dalam selama 20 menit disebutkan bahwa tidak terdapat perbedaan yang signifikan antara relaksasi nafas dalam dan kompres hangat dalam menurunkan Sakit Sakit Haid.

Penelitian lain yang mendukung penelitian tentang pengaruh relaksasi nafas dalam terhadap intensitas Sakit Sakit Haid adalah penelitian yang dilakukan oleh Retno Wida Hapsari dan Tri Anasari (2013). Dimana dalam penelitian tersebut peneliti membandingkan relaksasi nafas dalam dengan pemberian coklat. Penelitian tersebut dilakukan pada 15 responden yang mengalami Sakit Haid primer dengan metode relaksasi nafas dalam yang sama dengan penelitian ini. Hasil akhir menunjukkan bahwa responden mengalami penurunan intensitas Sakit yang signifikan dengan nilai signifikansi $p=0,000$. Hasil akhir dalam penelitian tersebut menyebutkan bahwa relaksasi nafas dalam lebih efektif terhadap penurunan intensitas Sakit Sakit Haid dibandingkan dengan metode pemberian cokelat. 
Hal ini juga diperkuat dengan dilakukannya sebuah penelitian oleh Vetty Priscilla, dkk (2012) dengan judul penelitian tentang perbedaan pengaruh nafas dalam dengan kompres hangat dalam menurunkan dismenore pada remaja di SMA Negeri 3 Padang dengan jumlah responden 32 remaja putri yang dibagi menjadi dua kelompok intervensi dan durasi relaksasi nafas dalam selama 20 menit disebutkan bahwa tidak terdapat perbedaan yang signifikan antara relaksasi nafas dalam dan kompres hangat dalam menurunkan Sakit dismenore (Priscilla, dkk, 2012)

Penelitian lain yang mendukung penelitian tentang pengaruh relaksasi nafas dalam terhadap intensitas Sakit dismenore adalah penelitian yang dilakukan oleh Retno Wida Hapsari dan Tri Anasari (2013). Dimana dalam penelitian tersebut peneliti membandingkan relaksasi nafas dalam dengan pemberian coklat. Penelitian tersebut dilakukan pada 15 responden yang mengalami dismenore primer dengan metode relaksasi nafas dalam yang sama dengan penelitian ini. Hasil akhir menunjukkan bahwa responden mengalami penurunan intensitas Sakit yang signifikan dengan nilai signifikansi $p=0,000$. Hasil akhir dalam penelitian tersebut menyebutkan bahwa relaksasi nafas dalam lebih efektif terhadap penurunan intensitas Sakit dismenore dibandingkan dengan metode pemberian cokelat (Hapsari dan Anasari T, 2013).

Dismenore yang dialami responden sesaat sebelum dilakukan teknik relaksasi nafas dalam, keadaan responden tidak rileks dan pikiran responden hanya tertuju pada Sakit tanpa melakukan relaksasi terhadap Sakit yang dirasakan Teknik relaksasi nafas dalam yang dilakukan oleh responden hanya berfokus pada daerah yang mengalami Sakit atau ketegangan otot pada perut bagian bawah dan merelaksasi perut bagian bawah yang mengalami Sakit atau ketegangan otot sampai responden mencapai relaksasi penuh.

Peneliti berasumsi bahwa kegiatan ini menciptakan suatu sensasi untuk melepaskan ketidak nyamanan dan stres. Secara bertahap, pasien dapat merelaksasikan otot tanpa harus menegangkan otot terlebih dahulu, maka otak akan mengaktivasi gelombang alfa di otak dan merangsang hipotalamus mengeluarkan hormone endorphine sehingga menimbulkan sehingga persepsi Sakit berkurang dan rasa cemas terhadap pengalaman Sakit menjadi minimal.

\section{Kesimpulan}

Berdasarkan hasil penelitian yang menunjukkan pengaruh antara teknik relaksasi napas terhadap Sakit haid pada remaja putri di UPTD Puskesmas Panglayungan Kota Tasikmalaya dengan tingkat signifikasi $\alpha=0.05$ diperoleh hasil $\mathrm{p}=0,002$ yang berarti $\mathrm{p}$ $<0,05$. Dari hasil tersebut remaja putri diharapkan untuk melakukan teknik relaksasi napas secara teratur bila merasakan Sakit saat haid, tidak memaksakan diri melakukan aktifitas hingga selesai agar badan tidak lelah. Peningkatan informasi sangat pentingdalam pengetahuan remaja, terkait kesehatan reproduksi, terutama ketika terjadi nyeri menstruasi. 


\section{Bibliografi}

Afroh F dan Mohamad Judha, Sudarti, (2012). Teori Pengukuran Sakit \& Sakit Persalinan, Yogyakarta : Nuha Medika

Andrarmoyo, Sulistyo, 2012. Keperawatan keluarga, Konsep Teori, Proses dan Praktik Keperawatan. Yogyakarta:Graha Ilmu

Ali Mohammad dan Mohammad Asrori. 2012. Psikologi Remaja Perkembangan Peserta Didik. Jakarta: PT. Bumi Aksara

Andarmoyo, Sulistyo. 2013. Konsep dan Proses Keperawatan Sakit.Yogyakarta: Ar-Ruzz Media.

Ariyani Ratna, 2009. Aspek Biopsikososial Hygiene Menstruasi pada Remaja di Pesantren As-Syafi iyah Bekasi. Skripsi FKM-UI

Atikah Proverawati dan Misaroh Siti.2009. Menarche Menstruasi Pertama Penuh Makna.Yogyakarta: Nuha Medika.

Azizah, N. (2013). Aplikasi Relaksasi Nafas Dalam Sebagai Upaya Penurunan Skala Sakit Menstruasi (Dismenorrhea) Pada Siswi Mts. Ibtidaul Falah Samirejo Dawe Kudus Tahun 2013. Jurnal Fakultas Kesehatan. Vol 5 No 1. Departemen Kesehatan RI. (1988). Kesehatan keluarga. Jakarta: Depkes RI.

Devi, N. (2012). Gizi saat sindrom menstruasi. Jakarta : PT Bhuana Ilmu Populer Kelompok Gramedia.

Dieny, Fillah. 2014. Permasalahan Gizi Pada Remaja Putri. Yogyakarta : Graha Ilmu Medika.

E, Kusmiran, 2012. Kesehatan Reproduksi Remaja dan Wanita. Jakarta: Salemba

Friedman, Marlyn. M, 1998. Keperawatan Keluarga, Edisi 3, Jakarta:EGC

Gusti, Salvari, 2013. Asuhan Keperawatan Keluarga. Jakarta: Trans Info Medika

Hapsari \& Anasari. 2013. Efektivitas teknik relaksasi nafas dalam dan metode pemberian cokelat terhadap penurunan intensitas dismenore pada remaja putri di SMK Swagaya 2 Purwokerto. Jurnal Involusi Kebidanan, Vol 3, no. 5, hh. 26-38

Hadisaputra, W \& Pramayadi, C, T. 2008. Masalah Gangguan Haid dan Infertilitas. Jakarta: FKUI

Idris, H. 2009. Perbedaan Sakit haid sebelum dan sesudah dilakukan Teknik Relaksasi Napas Dalam pada Mahasiswi S-1 Keperawatan Unimus. Semarang: Jurnal ebiomedik. Volume 4.

Kumbhar, S, K, Mrudula, R., Sujana, B., Roja,R, K., Divya,B, K dan BalkrishnaPrevalensi Dismenore Di antara Adolescent Girls (15 -19 thn) dari Distrik Kadapa dan Dampaknya pada Kualitas Hidup: Sebuah Studi Sectional Cross. Jurnal Nasional Community Medicine Vol 2 Edisi 2 Juli - 20 September 12

L, Sherwood. 2012. Fisiologi Manusia dari Sel ke Sistem. Edisi 6. Jakarta : EGC.h. 708-710

Manuaba. 2010. Ilmu kebidanan Penyakit Kandungan dan KB . Jakarta : EGC

Mitayani. (2012). Asuhan keperawatan maternitas. Jakarta : Salemba Medika. 
Nugroho, T dan Utama I.B. 2014. Masalah Kesehatan Reproduksi Wanita. Yogyakarta: Nuha Medika.

Nurarif .A.H. dan Kusuma. H. (2015). APLIKASI Asuhan Keperawatan Berdasarkan Diagnosa Medis \& NANDA NIC-NOC. Jogjakarta: MediAction

Nursalam, 2008. Konsep Dan Penerapan Metodologi Penelitian Ilmu Keperawatan. Edisi 2. Jakarta Salemba Medika

Notoatmodjo,S. (2012). Metodologi Penelitian Kesehatan. Jakarta : Rineka Cipta.

Padila, 2012. Buku Ajar Keperawatan Keluarga. Yogjakarta. Nuha Medika

Potter \& Perry, 2006. Fundamental Of Nursing. Proses Konsep dan Praktis.Edisi 4 Volume 2. Jakarta

Prasetyo, S. N. (2010). Konsep dan Proses Keperawatan Sakit. Yogyakarta : Graha Ilmu.

Sarwono. 2011. Psikologi Remaja.Edisi Revisi. Jakarta: Rajawali Pers.

Smeltzer, Suzanne C. dan Bare, Brenda G, 2002. Buku Ajar Keperawatan Medikal Bedah Brunner dan Suddarth (Ed.8, Vol. 1,2), Alih bahasa oleh Agung Waluyo. (dkk), EGC, Jakarta.

Sumiati, Dkk. 2009. Kesehatan Jiwa Remaja Dan Konseling. Jakarta: Trans Info Media. Undang-Undang Republik Indonesia Nomor 10 Tahun 1992 Tentang Perkembangan Kependudukan Dan Pembangunan Keluarga Sejahtera, Sejahtera, BKKBN, Jakarta, 1992. 